also require greater freedom for individual airlines to fly to international airports outside their own territory, which would entail some change of the present system under which airline routes are negotiated between governments with all the solemnity of disarmament treaties, but that would only be another advantage. Indeed, if the airlines could win for themselves more freedom on fares and routes, it would be well worth their clinching with governments an agreement that public money would not in future be used to subsidize the operation of international airlines. That is the third ingredient necessary to allow the economics of airline operations to find its proper level.

\title{
Time to Close the English Channel
}

IN the past few weeks, the English Channel has become less of a seaway than a hazard to shipping. Mariners and civil servants are fond of saying that the channel is the busiest shipping route in the world and this, indeed, seems to be a fact. Several hundred ships pass each way each day and one measure of the rate at which the traffic in the channel is increasing is the rate at which collisions seem to be occurring. On the face of things, of course, it would be reasonable to expect that the frequency of collision would be proportional to the square of the volume of traffic, or at least to the product of the volume of traffic in each direction. In practice, however, the nature of the channel and the rules which exist for regulating traffic there make the probability of collision much greater. First, sandbanks in the channel do necessarily confine ships to comparatively narrow tracks. Second, the rules promulgated by the shipping authorities for segregating opposing traffic into separate streams - westbound hard against the English coast and east bound on the other side-also require that opposing streams of traffic should cross at certain critical places. The result is that the problem of predicting collisions in the channel is not so much like the problem of predicting collisions between billiard balls on a smooth billiard table as that of predicting collisions between motor vehicles without brakes at road intersections without traffic lights. A little reflexion will show how fortunate it is that there has been comparatively little damage in the channel in the past few months-three vessels sunk, two damaged and one aground on the Goodwin Sands.

In spite of all the argument between Trinity House (which maintains lighthouses and lightships in British waters), the Admiralty and the shipowners about the best routing of traffic in the English Channel, there is every prospect that things will get worse before they can possibly become better. For one thing, there is an ambitious plan to develop a new port at the place at which it is almost certain that the government will be forced to choose for the third London Airport-Foulness in the Thames Estuary. Second, the Goodwin Sands (just two miles off the Kent coast) and the other underwater obstacles to navigation are likely to become more conspicuous as time goes on, if only because the channel continues to serve as a means by which solid material from the Atlantic can be deposited in the North Sea. In short, the time will come when the best way of avoiding mutual shipping damage in the channel will be to do away with the shipping. But even as things are, much of the shipping exists only because the channel exists. If there were a dam from Dover to Calais, or if the natural causeway which disappeared 6,000 years ago with the melting of the ice were still intact, cross-channel traffic would go by dry land, the great ports of Europe would probably lie nearby but Scandinavia would still be as close to South America because the route round Scotland to the northern ports is probably now as short in time as that through the Straits of Dover. So does it not make sense to ask whether the time has now arrived for getting rid of the English Channel, preferably by a dam that would yield electricity as well as a means of transport. By now, after all, it seems clear that the channel tunnel will not be built. In January, the British and French governments agreed on yet another device for postponing action-a scheme to spend $£ 10$ million on a further programme of research and development unlikely to be finished before 1974 . The two governments are right in their scepticism about the economic viability of a tunnel. If they wait long enough, they may even find that the channel clogs up without deliberate intervention with the hulls of all the ships likely to be sunk there by collisions in the next few years.

\section{Years Ago}

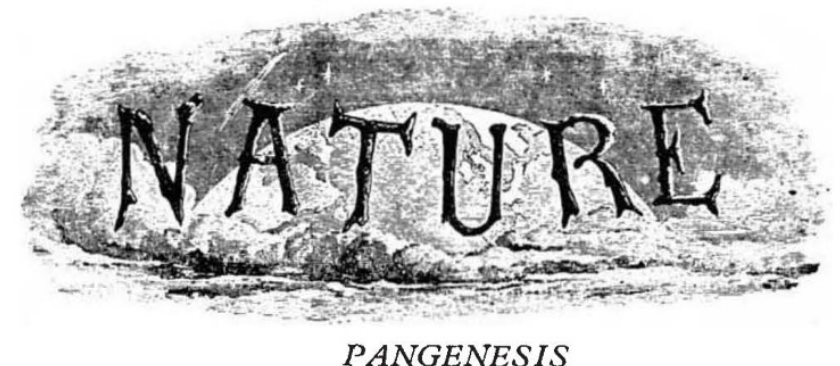

(Extract from a leader)

When, therefore, Mr. Galton concludes from the fact that rabbits of one variety, with a large proportion of the blood of another variety in their veins, do not produce mongrelised offspring, that the hypothesis of Pangenesis is false, it seems to me that his conclusion is a little hasty. His words are, "I have now made experiments of transfusion and cross circulation on a large scale in rabbits, and have arrived at definite results, negativing, in my opinion, beyond all doubt the truth of the doctrine of Pangenesis." If Mr. Galton could have proved that the reproductive elements were contained in the blood of the higher animals, and were merely separated or collected by the reproductive glands, he would have made a most important physiological discovery. As it is, I think every one will admit that his experiments are extremely curious, and that he deserves the highest credit for his ingenuity and perseverance. But it does not appear to me that Pangenesis has, as yet, received its death blow ; though, from presenting so many vulnerable points, its life is always in jeopardy ; and this is my excuse for having said a few words in its defence. CHARLES DARWiN 